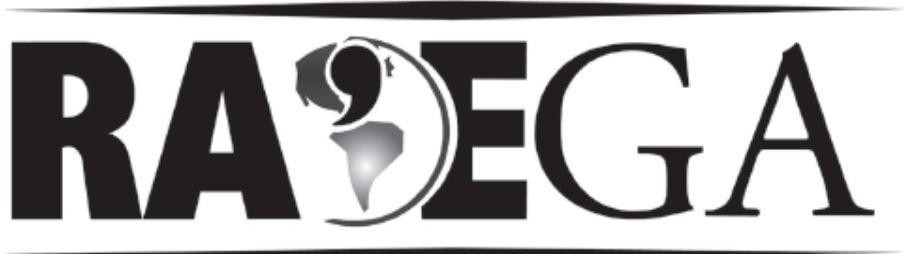

O ESPAÇO GEOGRÁFICO EM ANÁLISE

\title{
DINÂMICA E SUCESSÃO DOS PADRÕES DA PAISAGEM AGRÍCOLA NO MUNICÍPIO DE COCOS (BAHIA)
}

\section{DYNAMICS AND SUCCESSION OF AGRICULTURAL LANDSCAPE PATTERN IN THE MUNICIPALITY OF $\operatorname{COCOS}(B A H I A)$}

\author{
Fabiana de Oliveira Hessel ${ }^{1}$ \\ Osmar Abílio de Carvalho Junior² \\ Roberto Arnaldo Trancoso Gomes ${ }^{3}$ \\ Eder de Souza Martins ${ }^{4}$ \\ Renato Fontes Guimarães ${ }^{5}$
}

\section{RESUMO}

A necessidade de mapear e monitorar a superfície terrestre sobre uma amplitude de escalas temporais e espaciais é de importância primária na avaliação dos ecossistemas e para o planejamento do desenvolvimento sustentável. O presente trabalho objetiva analisar o processo de sucessão dos padrões de mudanças da paisagem no município de Cocos usando

\footnotetext{
${ }^{1}$ Mestre em Geografia pela Universidade de Brasília. Universidade de Brasília, UnB - Departamento de Geografia - Campus da Universidade de Brasília, ICC Ala Norte, CEP 70910-900, Brasília, DF.

Email: fabianahessel@yahoo.com.br

${ }^{2}$ Professor Doutor do Departamento de Geografia da Universidade de Brasília. Pesquisador CNPq - Nível 1B. Universidade de Brasília, UnB - Departamento de Geografia - Campus da Universidade de Brasília, ICC Ala Norte, CEP 70910-900, Brasília, DF. Email: osmarir@unb.br

${ }^{3}$ Professor Doutor do Departamento de Geografia da Universidade de Brasília. Pesquisador CNPq - Nível 2. Universidade de Brasília, UnB - Departamento de Geografia - Campus da Universidade de Brasília, ICC Ala Norte, CEP 70910-900, Brasília, DF. Email: robertogomes@unb.br

4 Pesquisador Doutor da EMBRAPA Cerrados. Pesquisador CNPq - Nível 2. Centro de Pesquisa Agropecuária dos Cerrados - Embrapa/CPAC. BR 020, Km 18, Rod. Brasília-Fortaleza. Caixa Postal 08223. CEP 73310-970, Planaltina, DF. Email: eder@cpac.embrapa.br

${ }^{5}$ Professor Doutor do Departamento de Geografia da Universidade de Brasília. Pesquisador CNPq - Nível 1C. Universidade de Brasília, UnB - Departamento de Geografia - Campus da Universidade de Brasília, ICC Ala Norte, CEP 70910-900, Brasília, DF. Email: renatofg@unb.br
} 
sensoriamento remoto. O município localiza-se na região do Oeste da Bahia onde ocorre uma intensa expansão agrícola e do agronegócio devido às condições ambientais favoráveis com terras planas e estações de chuvas bem definidas. Imagens do sensor ALOS e Landsat 5 foram usadas para produzir os mapas de uso e cobertura da terra nos anos 1996, 2000, 2004 e 2008. A metodologia proposta possui as seguintes etapas: (a) pré-processamento das imagens; (b) classificação do uso e cobertura da Terra por interpretação visual e detecção de mudança usando o método de pós-classificação; (c) análise multitemporal das infraestruturas; e (d) identificação do seqüenciamento dos padrões relativos à transformação dos ambientes naturais em antrópicos. A agropecuária apresenta uma forte tendência de crescimento ao longo do tempo, sendo o principal vetor de alteração da paisagem natural. Observa-se um processo crescente da conversão do Cerrado em áreas agrícolas. 0 aumento de rodovias é um importante indicador do advento da paisagem agrícola. Apesar do município ainda possuir extensas áreas preservadas, as localidades de ocupação agrícola apresentam a completa devastação do Cerrado. Essas mudanças do uso da terra possuem implicações na conservação do Cerrado e no manejo de uma agricultura sustentável.

Palavras chaves: Sensoriamento Remoto; Processamento de Imagens; Análise Multitemporal; Detecção de Mudança; Cobertura da Terra; Monitoramento da Vegetação.

\begin{abstract}
The need to map and monitor the surface, over a range of spatial and temporal scales, is of prime importance in assessing the status of ecosystems and planning for sustainable development. The present paper aims to analyze the succession process of landscape change patterns in Cocos municipality using remote sensing data. The municipality is located in the West Bahia, where there is a strong expansion of agriculture and agribusiness due to the environmental conditions favorable with flat lands and a well-defined rainy season. ALOS and Landsat 5 images are used to produce land use cover maps for the years 1996, 2000, 2004 and 2008. The proposed methodology has the following steps: (a) pre-processing; (b) land use classification by visual interpretation and the determination of differences between temporal images using the postclassification change detection method; (c) multitemporal analysis of infrastructures; and (d) identification of landscape change patterns during the conversion of Cerrado to agricultural land. The agricultural sector presents a strong growth trend over time, the main vector for change in the natural landscape. There is a consistent trend for the landscape change patterns in the conversion of Cerrado to agricultural areas. Increased road is an important indicator of the advent of the agricultural landscape. Although the municipality still has large areas preserved, the locations of agricultural occupation have a complete devastation of the Cerrado. These land use changes have implications for Cerrado conservation and management of sustainable agriculture.
\end{abstract}

Keywords: Remote Sensing; Image Processing; Multitemporal Analysis; Change Detection; Land cover; Vegetation monitoring. 


\section{INTRODUÇÃO}

A intervenção humana tem estreita relação com o ecossistema, induzindo processos interativos e de sucessão que modificam a paisagem. A paisagem integra as categorias geográficas, constituindo-se como embasamento para os estudos ambientais e de organização do espaço em bases sustentáveis. Conforme Bertrand (1968), a paisagem é considerada como um grupo de formas, objetos e elementos que definem um espaço geográfico e dentro de seus limites ocorre as inter-relações dos fatores humanos e ambientais.

Esta abordagem holística entre o desenvolvimento social, econômico e qualidade do meio ambiente é prevista pela Constituição Federal de 1988 (BRASIL, 2003), que coloca o meio ambiente no foco das decisões políticas. Os acordos multilaterais e as convenções, dos quais participam o Brasil, reforçam o compromisso constitucional de proteger os ecossistemas, a biodiversidade e o patrimônio genético do país (BRASIL, 2002). O princípio da prevenção da política ambiental nacional estrutura-se na manutenção das características ecológicas da região, e direciona as ações de planejamento e ordenamento territorial, diminuindo a necessidade de ações retificadoras (recuperação), que constituem ações de maior complexidade e custos.

A proposta de sustentabilidade abrange a necessidade de continuidade e permanência da qualidade de vida, sem perder de vista uma perspectiva de longo prazo. O desenvolvimento sustentável baseia-se no tripé estrutural: prudência ecológica, eficiência econômica e justiça social (SACHS, 2004). A prudência ecológica consiste na manutenção dos ambientes naturais, levandose em conta a continuidade, a regularidade da atividade econômica e a qualidade do meio ambiente. A eficiência econômica consiste na capacidade de produzir mais e melhor com economia de recursos, capital e trabalho. Por fim, a justiça social consiste em igualdade de oportunidades.

A análise do ambiente pode ser realizada considerando-o como um sistema, ou seja, um conjunto de elementos que se relacionam entre si, com certo grau de organização, o que lhe confere o estado e a função de um todo 
(XAVIER-DA-SILVA, 2001). Para adequação deste conceito ao meio ambiente é introduzido o termo geossistema, um tipo particular de sistema aberto resultante da interação dos elementos naturais, sociais, econômicos, políticos e culturais na superfície terrestre, que representa a realidade socioambiental de uma região (SOTCHAVA, 1977; SALES, 2004).

A abordagem sistêmica nos estudos ambientais acompanha a produção dos modelos de representação da realidade. A simplificação formal da complexidade ambiental e social pode ser realizada pelo emprego da teoria matemática, técnicas computacionais e geotecnologias. Neste propósito, a análise das feições cartográficas a partir de imagens de satélite consiste em uma importante fonte de informações espaciais acerca da paisagem (MARTINELLI, 1991). O uso de imagens de satélite possibilita a redução do tempo de análise e observação dos fenômenos, apresentando dados atualizados e com grande confiabilidade (SAMPAIO, 2007; BENITE, 2006). A partir das imagens são extraídos elementos básicos de objetos, áreas ou fenômenos considerando os atributos relativos ao comportamento espectral dos alvos, texturas, estruturas e padrões de formas (ARAÚJO FILHO et al., 2007; CREPANI et al., 2001).

A análise multitemporal por sensoriamento remoto permite compreender e remontar o processo histórico de ocupação do espaço geográfico fornecendo subsídios para detectar e prever problemas e demandas. Portanto, esta ferramenta torna-se imprescindível para o estabelecimento de um sistema de gestão e monitoramento do uso dos recursos naturais, principalmente nos ambientes de alta dinâmica humana.

O objetivo do presente trabalho é analisar o processo de sucessão dos padrões de mudanças da paisagem no município de Cocos, localizado na região do Oeste da Bahia onde ocorre uma intensa expansão agrícola e do agronegócio. Ao contrário de outros municípios da região, o município de Cocos apresenta uma baixa ocupação humana, o que permite uma atuação preventiva de forma a não repetir os mesmos impactos negativos dos municípios circunvizinhos. A incorporação e a padronização dos agrossistemas presentes em outros municípios, como o de Luis Eduardo Magalhães (MENKE 
et al. 2009), é um fator preocupante, pois apresenta extensas áreas contínuas de agricultura sem a manutenção do Cerrado nativo.

Devido às características da área de estudo o presente trabalho apresenta uma adequação metodológica da análise temporal. Normalmente, os estudos de análise multitemporal em áreas agropecuárias enfocam principalmente o balanço de perda das áreas naturais pelo uso antrópico. Nesta situação o dano ambiental já foi realizado com o corte da vegetação natural exigindo maior esforço e custos para reparação ambiental. Neste artigo, além da análise corriqueiramente utilizada da evolução das áreas plantadas, é definida uma metodologia que enfoca os atributos espaciais de infra-estrutura que indiquem e antecipem os processos de ocupação. Neste contexto, é adotada a análise do aumento de estradas (pavimentadas ou de terra), sedes agrícolas e reservatórios, buscando definir um encadeamento e uma sucessão de usos da terra até a implantação agrícola.

\section{ÁREA DE ESTUDO}

O município Cocos era originalmente ocupado por índios caiapós, sendo o seu nome uma referência à abundância de coco babaçu na região. O município foi criado pela Lei Estadual número 1.025 de 14 de agosto de 1958. Ocupa uma área de $10.084 \mathrm{~km}^{2}$, representando aproximadamente $1,8 \%$ do território baiano (BAHIA, 2007). O município pertence à região econômica do Oeste Baiano e à microrregião político-administrativa de Santa Maria da Vitória. É limítrofe aos municípios de Jaborandi, Coribe e Feira da Mata (BA), Sítio da Abadia (GO) e Montalvânia, Bonito de Minas, Januária e Formoso (MG) (Figura 1). 


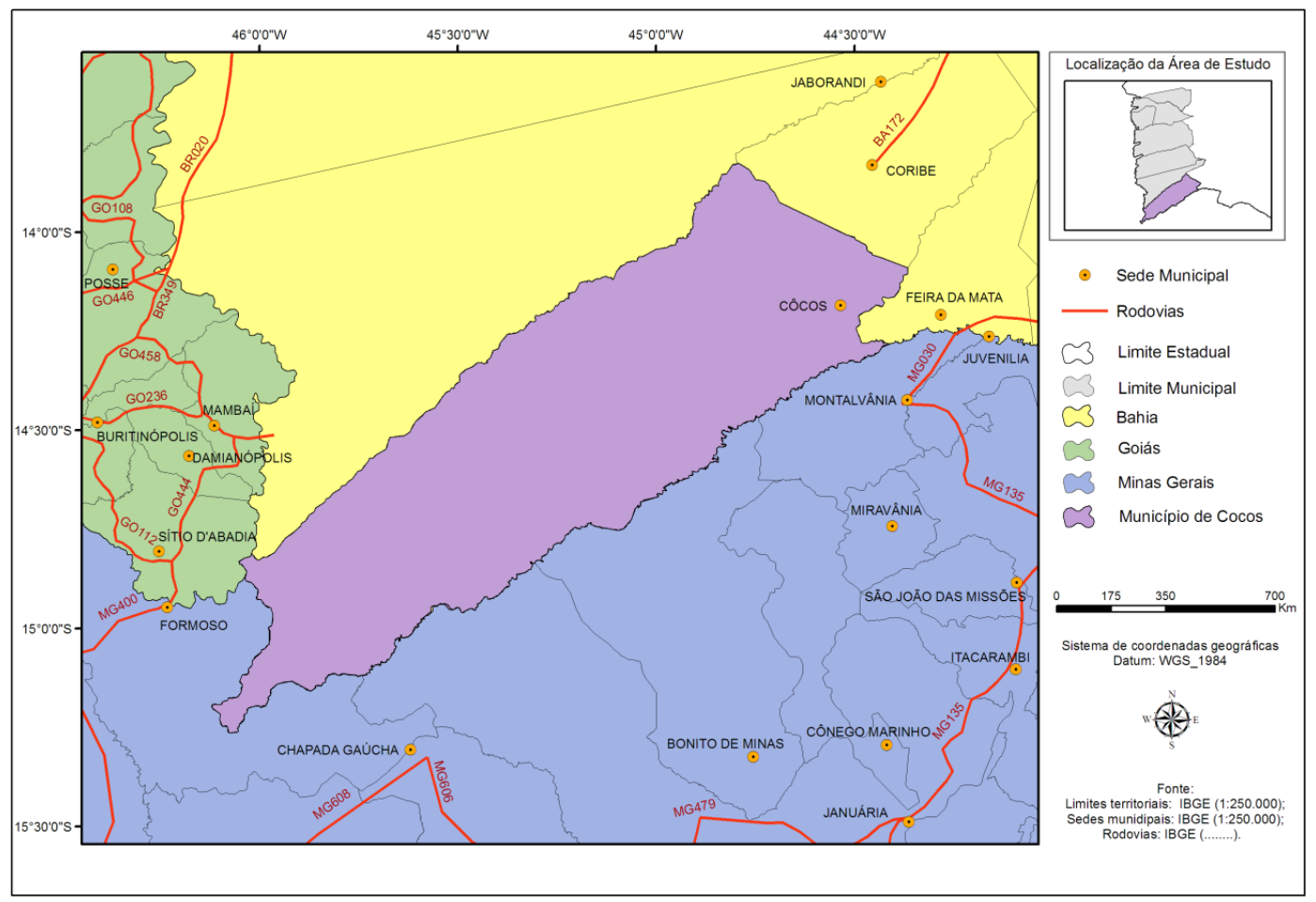

Figura 1 - Localização do município de Côcos situado no extremo sul da região do Oeste da Bahia.

O clima no oeste da Bahia é tropical com chuvas sazonalmente distribuídas, com variação geográfica no sentido leste-oeste, e totais pluviométricos de $1000 \mathrm{~mm}$ anuais e temperaturas médias anuais entre $18 \mathrm{e}$ 22C (FELFILI \&SILVA-JÚNIOR, 2001). Dois tipos climáticos são identificados no município: (a) Clima Tropical Úmido de savana na porção oeste, com alternância regular da estação úmida e da estação seca e excedente hídrico acima de 600 milímetros anuais; (b) Clima Tropical Subúmido Seco na porção centro-leste, adjacente ao Clima Semi-Árido, com médias pluviométricas menores e excedentes hídricos entre 300 e 600 milímetros anuais. Ambos têm regime pluviométrico concentrado na primavera e no verão, com prolongamento da estação seca.

No município de Cocos, a cobertura vegetal é predominantemente savânica com incidência de Floresta Estacional Decidual na porção sudeste 
(SANTANA et al., 2010). A Savana Arbórea Aberta (Cerrado Senso Restrito) possui a maior extensão de área no município, sendo caracterizada pela presença de dois estratos de vegetação: herbáceo e arbustivo-lenhoso. Esta fitofisionomia caracteriza-se por árvores baixas, tortuosas e retorcidas, com troncos cortiçosos, folhas rígidas e coriáceas (xeromorfismo); esparsamente distribuídas sobre o tapete gramíneo-lenhoso; podendo estar associadas ou não a Florestas de Galeria (RIBEIRO \& WALTER, 1998). A Savana Parque ocupa áreas no oeste e nordeste do município e caracteriza-se pelo predomínio de gramíneas acompanhadas por uma cobertura arbórea esparsa, que oscila entre 5 e 20\% (RIBEIRO \& WALTER,1998). As formações campestres aparecem concentradas no noroeste, sendo caracterizada pelo predomínio da vegetação herbácea e presença esparsa de arbustos (RIBEIRO \& Walter, 1998). A Floresta Estacional Decidual Montana (Mata Seca) concentrada na porção sudeste da área, caracterizando-se por diferentes tipos de caducifolia associadas às condições físicas, químicas e de profundidade do solo. $O$ estrato arbóreo apresenta-se entre 15 e 30 metros, com cobertura entre 70 e 95\% na estação chuvosa, e menos de $50 \%$ na estação seca (FELFILI \& SILVAJúNIOR, 2001).

A área do município de Côcos tem relevância ambiental devido o grande remanescente de Cerrado, uma das 25 áreas do mundo mais ricas em biodiversidade e consideradas críticas para a conservação devido à alta pressão antrópica (KLINK \& MACHADO, 2005). No entanto, essas áreas preservadas estão ameaçadas, devido à expansão do agronegócio que obtém nesta região características ambientais favoráveis ao seu desenvolvimento. Nas regiões de Chapadas, o solo é caracterizado por ser muito drenado, arenoso e por se localizar em relevo plano, condições propícias para a implantação da agricultura intensiva e mecanizada. A relativa escassez de água durante o período de seca é suprida por irrigação com a utilização das águas dos tributários do Rio São Francisco, perenes e de boa vazão, ou do aquífero Urucuia, sob forma de poços tubulares profundos. A conjunção de terras propícias à mecanização e à existência de água para irrigação caracteriza condições ideais para o agronegócio, cujos principais cultivos são 
soja, algodão, milho, café, fruticultura, feijão, arroz e forrageiras para o gado (MENKE et al, 2009). Outros municípios do Oeste da Bahia com condições ambientais similares apresentam a maior expansão agrícola do Estado das últimas décadas.

O município apresenta uma população eminentemente rural com 17.637 habitantes conforme o último Censo do IBGE relativo ao ano de 2000, com estimativa para o ano 2008 de 17.908 habitantes, representando aproximadamente $0,13 \%$ da população baiana. A densidade demográfica é de 1,85 habitantes $/ \mathrm{km}^{2}$, extremamente baixa comparada com a densidade demográfica do Estado, que é de 24,47 habitantes $/ \mathrm{km}^{2}$. Recentemente, o município apresenta um cenário de transformações de suas estruturas econômicas e sociais com intensificação do processo de urbanização e do desenvolvimento agrícola induzido pelo agronegócio. Indicadores econômicos apresentam um crescimento significativo do município, especialmente nas últimas décadas, como pode ser observado pela evolução do PIB municipal (Tabela 1).

Tabela 1. Evolução do PIB no Município de Cocos, BA, entre 2002 e 2005.

\begin{tabular}{|c|c|c|}
\hline Ano & $\begin{array}{c}\text { PIB a preços correntes } \\
(\mathbf{1 0 0 0} \mathbf{R} \mathbf{)})\end{array}$ & Plb per capita (R\$) \\
\hline 2002 & 55625 & 3767 \\
\hline 2003 & 68760 & 4370 \\
\hline 2004 & 80615 & 5675 \\
\hline 2005 & 105732 & 378 \\
\hline
\end{tabular}

Fonte: IBGE (2007).

\section{MATERIAL E MÉTODOS}

A metodologia proposta possui as seguintes etapas: (a) aquisição das imagens de alta resolução espacial PRISM/ALOS e da série temporal TMLandsat; (b) pré-processamento das imagens; (c) classificação do uso e cobertura da Terra e detecção de mudança usando o método de pós- 
classificação; (d) análise multitemporal das infraestruturas; e (e) identificação do seqüenciamento dos padrões relativos à transformação dos ambientes naturais em antrópicos.

\section{Imagens do sensor PRISM/ALOS e TM-Landsat}

No presente trabalho foram utilizadas imagens de alta resolução do sensor PRISM/ALOS referente ao ano de 2008 e uma série temporal de imagens do sensor TM/Landsat relativos aos anos de 1996, 2000, 2004 e 2008.

O satélite japonês ALOS (Advanced Land Observing Satellite) foi lançado em 24 de janeiro de 2006, entrando na fase operacional em 20 de outubro de 2006, após um período de calibração. O ALOS descreve uma órbita circular heliossíncrona. Este satélite carrega três sensores: o AVNIR-2 (Advanced Visible and Near-Infrared Radiometer - Type 2), o PALSAR (Phased Array L-band Synthetic Aperture Radar) e o PRISM (Panchromatic Remote-sensing Instrument for Stereo Mapping) (KOCAMAN \& GRUEN, 2008).

As imagens de alta resolução espacial utilizadas no presente trabalho são do sensor PRISM que opera na faixa do visível com uma banda pancromática. Trata-se de um conjunto de três sistemas de imageamento que permite obter simultaneamente imagens com visada nadir, inclinada para frente e inclinada para trás (Triplet), o que torna possível a aquisição de imagens estereoscópicas ao longo da trajetória. As imagens ALOS/PRISM são de alta resolução, 2,5 metros, possibilitando mapeamentos detalhados, como na escala 1: 25.000 (IGARASHI, 2001; KOCAMAN \& GRUEN, 2008). A largura da faixa de imageamento é de $35 \mathrm{~km}$ no modo de observação estéreo e de $70 \mathrm{~km}$ em observação nadir com resolução espacial de 2,5 m.

Nesta pesquisa foram adquiridas imagens pré-processadas referentes ao produto 1B2 das imagens PRISM, que passaram por calibração radiométrica e geométrica, onde os pixels são alinhados com a grade da projeção UTM. O erro médio quadrático da precisão geométrica absoluta para a visão nadir é de $8 \mathrm{~m}$ (cross track) e $9 \mathrm{~m}$ (along track), enquanto que a precisão relativa é de $4 m$ (cross trtack) e $3 m$ (along track) (JAXA, 2006). Para a 
cobertura de toda a área do município de Cocos foram utilizadas 21 cenas em diferentes datas entre março e junho de 2007 e 2008.

O programa LANDSAT (Land Remote Sensing Satellite) foi desenvolvido pela NASA (National Aeronautics and Space Administration) no início dos anos 70. Dentre os sete satélites do programa, atualmente apenas o Landsat-5 encontra-se em operação carregando a bordo o sensor TM (Thematic Mapper) (ROSA, 1992). As imagens foram adquiridas gratuitamente no banco de imagens digitais do Instituto Nacional de Pesquisas Espaciais presentes no site: <http://www.dgi.inpe.br/CDSR>. A seleção das imagens dependeu dos seguintes fatores: a disponibilidade no banco de dados, o período de aquisição (estação seca) e a quantidade de nuvens presentes (inferior a 30\%). Para a área de estudo foram utilizadas duas cenas relativas às seguintes órbita-ponto e datas: $219 / 070$ (03/09/2008; 23/08/2004; 12/08/2000; 29/05/1996) e 220/070 (10/09/2008; 27/08/2004; 16/08/2000; 21/06/1996). As imagens foram escolhidas na mesma época do ano de forma a evitar alterações provenientes das mudanças sazonais como as características fenológicas das plantas.

\section{Pré - processamento}

As principais etapas de pré-processamento requeridas foram: (a) coregistro entre as imagens temporais, e (b) confecção do mosaico. O co-registro consiste uma etapa primordial para garantir a acurácia da detecção de mudança. Para a análise multitemporal o erro médio quadrático adequado é que seja inferior que a metade da dimensão do pixel para evitar a presença de uma mudança irreal proveniente apenas da imprecisão do registro (TOWNSHEND et al., 1992; DAI \& KHORRAM, 1998). Para este trabalho as imagens TM-Landsat 5 foram co-registradas usando o programa ENVI e as imagens Geocover a partir de pontos de controle imagem para imagem. $O$ conjunto de dados Landsat GeoCover é uma coleção de resolução moderada ortorretificada. Os dados estão disponíveis para a maior parte do globo, a partir da Global Land Cover Facility (MDA FEDERAL, 2004). Os mosaicos foram confeccionados a partir das imagens registradas a partir do programa ENVI. 


\section{Detecção de Mudança utilizando o procedimento de Pós-Classificação.}

Os métodos de detecção de mudança buscam identificar alterações no estado de um objeto, ou nas feições da superfície terrestre, entre imagens de diferentes datas (SINGH, 1989). Os métodos de detecção de mudança podem ser subdivididos em dois tipos: (a) emprego de imagens discretas no tempo de uma mesma região, normalmente um conjunto bi-temporal, com o objetivo de identificar mudanças espaciais na cobertura da terra (WEISMILLER et al., 1977, BYRNE et al., 1980; FUNG \& LEDREW, 1987); e (b) emprego de séries temporais contínuas que permite descrever a dinâmica e evolução superficial (REED et al., 1994; MORA \& IVERSON, 1997, CARVALHO JÚNIOR et al 2006, 2008, LATORRE et al., 2006). O presente trabalho está inserido na primeira abordagem, que apresenta uma maior representatividade entre os métodos de detecção de mudança. Por sua vez, os métodos discretos podem ser subdivididos em dois subtipos (JENSEN et al., 1993, YUAN et al., 2005): (a) pré-classificação e (b) pós-classificação.

Os métodos de pré-classificação efetuam um processamento digital dos dados temporais para realçar as áreas de mudança, como: operações algébricas (ex. GONG et al., 1992; COPPIN et al., 2001; SKAKUN et al., 2003), transformações lineares (ex. BYRNE et al., 1980; CAKIR et al., 2006) e medidas espectrais (ex. CARVALHO JÚNIOR et al., 2011). O procedimento de classificação é normalmente realizado pela determinação do valor digital limite entre as classes de mudança e não mudança nas imagens realçadas (ex. FUNG \& LEDREW, 1988; MACLEOD \& CONGALTON, 1998, MAS 1999).

No método de pós-classificação, as imagens temporais são previamente classificadas, individualmente, de forma manual ou por métodos computacionais e depois são comparadas extraindo as áreas de mudança (GORDON, 1980; HOWARTH \& WICKWARE, 1981; DE BRUIN, 2000; MUNYATI, 2000). As principais vantagens do método de pós-classificação são: (a) fácil atualização ao longo do tempo favorecendo o monitoramento; (b) permite compensar as variações provenientes das condições atmosféricas, 
mudanças fenológicas e umidade de solo, devido à independência na confecção do mapa temático; e (c) permite integrar e comparar imagens de sensores com diferentes resoluções espaciais, espectrais, temporais e radiométricas (COPPIN et al., 2004; NARUMALANI et al., 2004, MENKE et al., 2009). As principais desvantagens deste método são as seguintes: (a) não é completamente automático, tornando-se um processo mais lento; e (b) a precisão da detecção das mudanças depende da acurácia da classificação em cada tempo, o que pode facilitar a propagação de erros (MENKE et al., 2009).

No presente trabalho, com o propósito de obter uma detecção de mudança mais acurada possível foi adotado o método de pós-classificação por interpretação visual em tela balizada por extenso trabalho de campo e informações obtidas juntos aos agricultores. A classificação visual foi realizada inicialmente nas imagens de alta resolução espacial do sensor PRISM. A partir disso, realizou-se uma retroanálise por interpretação visual das imagens TMLandsat para os anos anteriores. Deve-se ressaltar que esta metodologia a partir da interpretação visual sobre imagens de alta resolução combinado ao trabalho de campo é normalmente utilizada como verdade terrestre para validar os métodos de pré-classificação, que possuem como maior vantagem a automação e a rapidez (RIDD \& LIU, 1988; COHEN et al., 1998, SADER et al. 2003). Assim, apesar da morosidade, a metodologia adotada permite obter resultados bastante fidedignos à realidade.

No mapeamento do uso e cobertura da terra, foram adotadas as seguintes classes: vegetação natural (vegetação nativa preservada e vegetação alterada), agropecuária (agricultura, pivô central e pecuária), áreas urbanas (cidades e vilas/povoado), corpos d'água e áreas degradadas.

\section{Análise Multitemporal dos atributos de infraestrutura.}

Além da análise areal das classes do mapa de uso e cobertura da terra é também avaliada a evolução temporal dos atributos de infraestrutura relativos à extensão de estradas (pavimentadas ou de terra), número de sede de propriedades e número de reservatórios. Esta informação permite descrever o 
processo de ocupação e muitas vezes antecipar o intuito de uso antes da instalação das atividades agropecuárias.

As estradas são consideradas o principal vetor de ocupação agropecuária reduzindo o isolamento de comunidades rurais e melhorando a qualidade de vida. No entanto, ambientalmente ocasiona a fragmentação da paisagem, uma subdivisão de um grande habitat em parcelas menores, que modificam extensas áreas de vegetação natural resultando em um mosaico de ambientes fragmentados e isolados (FORMAN, 1995). Muitas espécies de animais não conseguem manter suas populações em pequenos fragmentos (machas), o que os leva à extinção e conseqüentemente perda da biodiversidade. As rodovias são consideradas a maior causa de fragmentação e de impactos ecológicos, como: (1) perda do habitat; (2) aumento do número de fragmentos e diminuição do tamanho dos fragmentos; (3) efeito de borda; (4) dispersão de algumas espécies específicas; (5) morte de animais devido aos veículos nas rodovias; (6) barreira para a dispersão de certos organismos e concomitantemente o isolamento destes; (7) perturbação intensiva devido ao tráfego nas rodovias; (8) facilita o acesso humano e conseqüentemente a caça; (9) facilita a erosão do solo e queimadas e (10) perturbação do processo hidrológico (SAUNDERS et al., 2002; MATTOS et al. 2003). Desta forma, a análise dos padrões de crescimento agropecuário e urbano a partir das estradas apresenta relevância na compreensão da ocupação humana, sendo muito utilizada na região Amazônica (LAURENCE et al., 2002; BATISTELLA et al., 2003; SOUZA JUNIOR et al., 2004; PERZ et al., 2005; FERREIRA et al., 2005).

Complementarmente, no presente estudo foram também mapeadas as sedes de propriedades e reservatórios, outros indicadores que permitem detectar a instalação e fixação humana na região.

As estradas pavimentadas e de terra, sedes e reservatórios foram vetorizadas na escala de 1:50.000 usando como base o mosaico das cenas do PRISM para a data mas recente. Os demais anos (2004, 2000 e 1996) foram editados em ordem cronológica decrescente, eliminando as estradas inexistentes nos mosaicos relativos ao sensor TM-Landsat. Dessa forma foi 
possível obter um arquivo vetorial das infraestruturas ao logo do tempo na área estudada.

Seqüenciamento dos padrões de transformação dos ambientes naturais em antrópicos.

A agricultura é historicamente um dos pilares de sustentação do modelo econômico e social atual, definindo formas de produzir e organizar o território. Para prever o comportamento de uso e cobertura das terras é preciso estabelecer um modelo considerando o papel das variáveis sociais e econômicas ao longo do tempo. A ocupação humana apresenta uma sucessão de apropriações que se manifestam em padrões de uso detectáveis em trajetórias e ciclos de desenvolvimento. No presente estudo a partir da sucessão de uso da terra e dos indicativos dos padrões de infraestrutura instalada será modelada uma seqüência dos padrões da paisagem relativos à apropriação do Cerrado pelas atividades agropecuárias. As técnicas da geoinformação são utilizadas para integrar analiticamente as trajetórias destas paisagens em transformação.

\section{RESULTADOS E DISCUSSÃO}

\section{Mapa de Uso da Terra- 1996}

O município de Cocos em 1996 era essencialmente uma paisagem natural com grandes áreas de vegetação (984.267 hectares - 97,60\%) (Figura 2). As áreas de vegetação em quase sua totalidade estavam preservadas (970.427,63 hectares - 96,24\%) com uma pequena porção alterada (13.834,56 hectares - 1,37\%). 


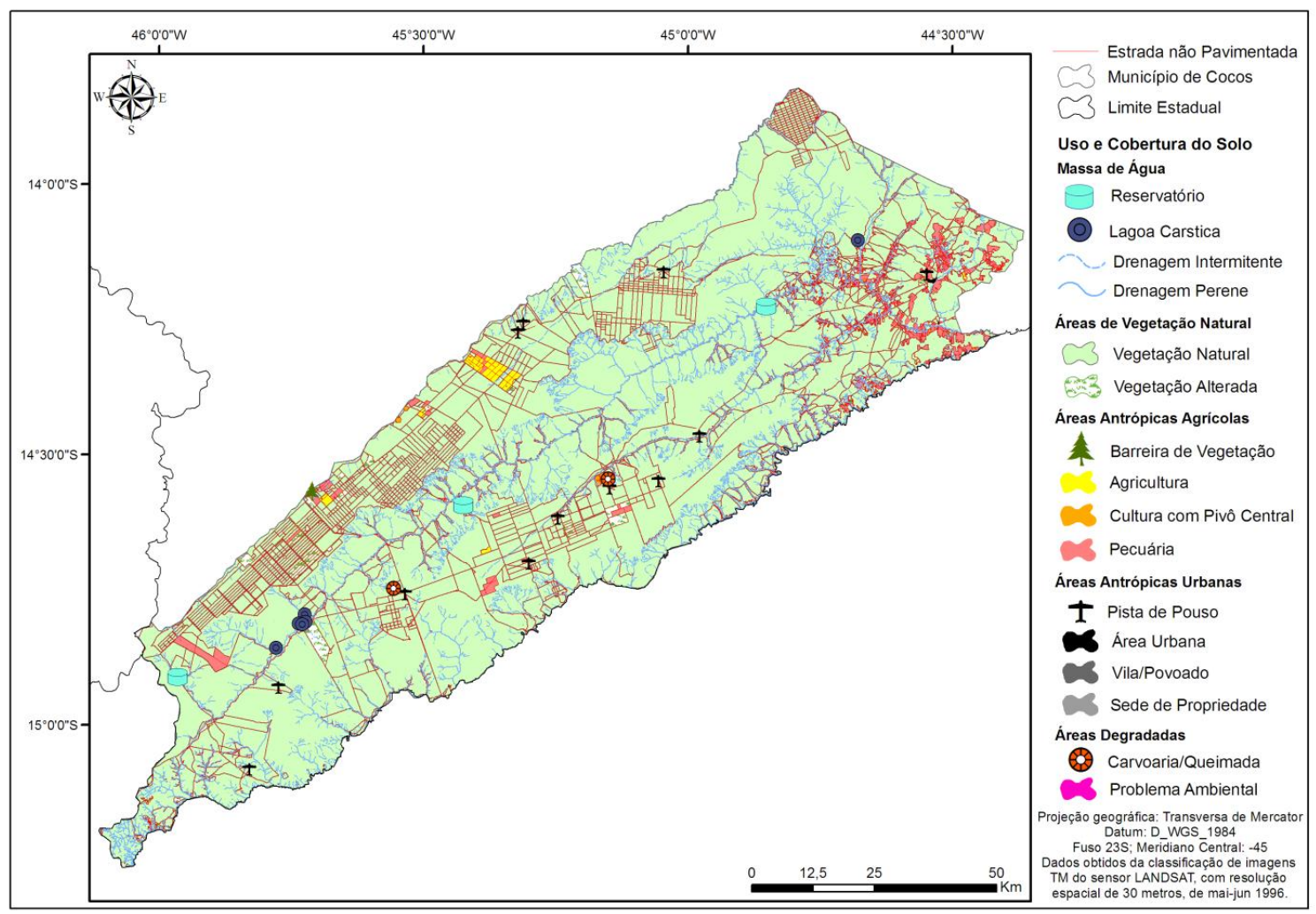

Figura 2 - Mapa de Uso e Cobertura do solo no município de Cocos, BA, em 1996.

As áreas de uso antrópico apareceram concentradas: nas regiões de chapada por grandes cultivos; e na região de vale próximo a sede municipal por agricultura familiar e pecuária. As áreas agropecuárias (22.886,85 hectares - 2,27\%) eram constituídas por: (a) agricultura perene e sazonal (4.438,29 hectares); culturas com pivô central (99,88 hectares); e pecuária (18.348,68 hectares). As áreas antrópicas urbanas possuíam pouca representatividade na área de estudo (62,74 hectares), sendo representadas por: cidade $(8,14$ hectares) e sete vilas e povoados (54,60 hectares).

As áreas degradadas $(53,22$ hectares $)$ eram compostas por carvoarias/queimadas e erosões/áreas desmatadas, sendo estas últimas as mais significativas (52,62 hectares), localizando-se próximas aos cursos de água, em áreas críticas para a conservação ambiental. Os corpos d'água (1.130 hectares) estão presentes em: três reservatórios situados no Rio Itaguari 
e seus afluentes (3 hectares); seis lagoas cársticas na porção oeste do município (2 hectares); e rios (1.125 hectares).

\section{Mapa de Uso da Terra- 2000}

No ano 2000 a quantidade de vegetação nativa permaneceu significativa (963.145 hectares - 95,51\%), mas apresentou redução em relação ao ano de 1996 (Figura 3). As áreas de vegetação alterada (9.033,65 hectares - 0,9\%) apresentaram uma queda em relação ao ano de 1996, devido à efetivação da agricultura nestas localidades. As áreas de vegetação preservada sofreram uma diminuição (954.111,58 hectares - 94,61\%).

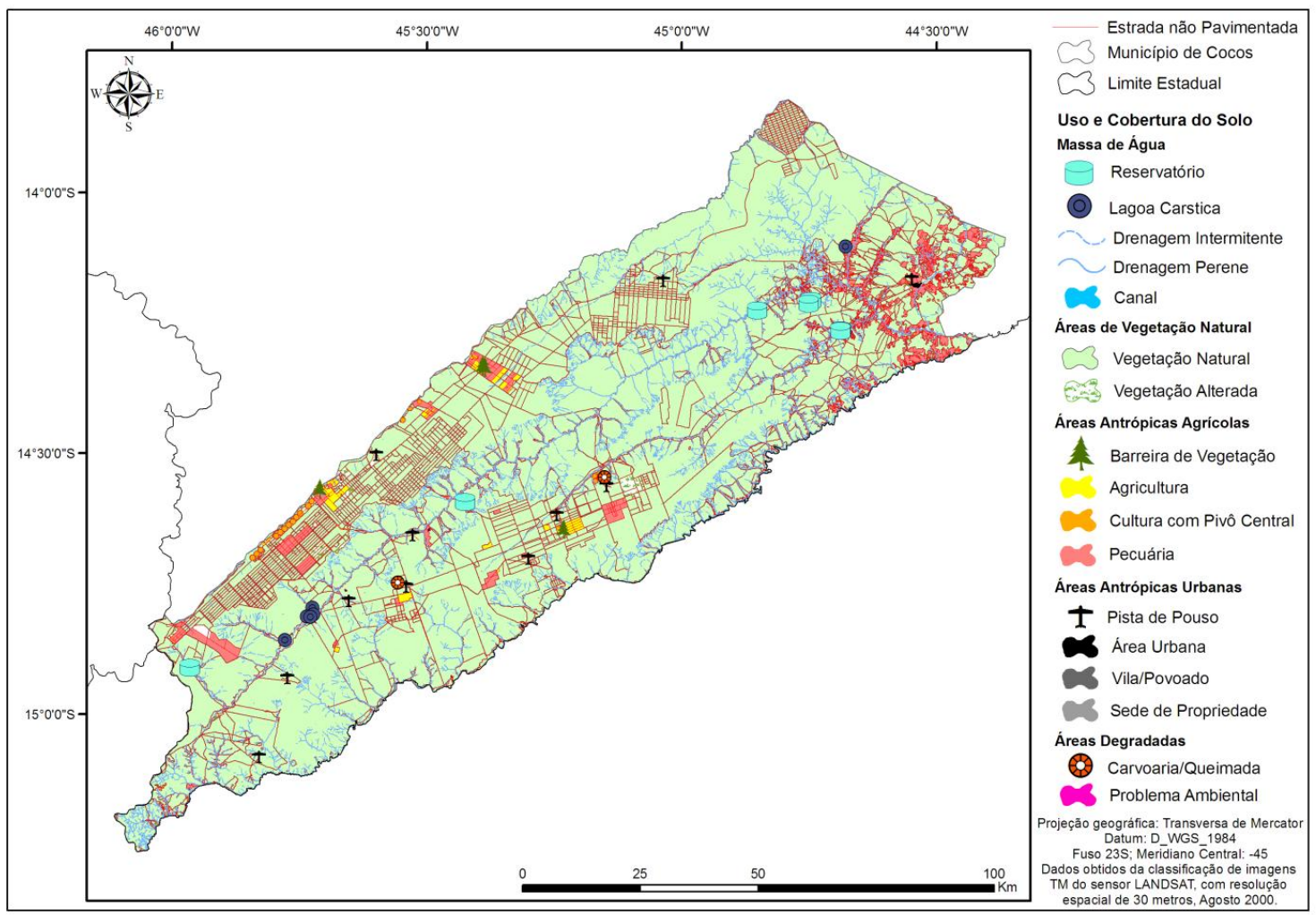

Figura 3 - Mapa de Uso e Cobertura do solo no município de Cocos, BA, em 2000.

As áreas antropizadas cresceram aproximadamente $100 \%$ em relação a 1996, tanto por áreas agrícolas (43.818,72 hectares - 4,35\%) como por áreas não-agrícolas (231,34 hectares - 0,023\%). Observa-se que o desenvolvimento antrópico do ano de 1996 ocorreu de forma distinta nas unidades 
geomorfológicas de Chapada e de Vale em relação à Depressão (Figura 4). As áreas de Chapada foram recortadas por estradas e apresentaram grandes propriedades agrícolas cultivadas. Na região de Vale, na porção sudeste, observou-se o adensamento urbano e a expansão da pecuária e agricultura de subsistência.

Todas as classes agropecuárias apresentaram crescimento. A pecuária praticamente dobrou $(35.866,76$ hectares - 3,56\%) e a agricultura apresentou um tênue crescimento nas áreas com parcelamento $(5.906,23$ hectares 0,59\%). As áreas com irrigação por pivô central apresentaram uma significativa expansão $(2.045,73$ hectares - 0,2\%), passando a ocupar grande parte das margens do Rio Formoso e do Rio Itaguari. As áreas antrópicas não-agrícolas também evidenciaram expansão: cidade de Cocos (164,03 hectares); e vilas e povoados (67,31 hectares). Os corpos d'água (1.135 hectares) apresentam 9 reservatórios ( 7 hectares) e 1 canal (1 hectare), além das 6 lagoas cársticas (2 hectares) e rios (1125 hectares).

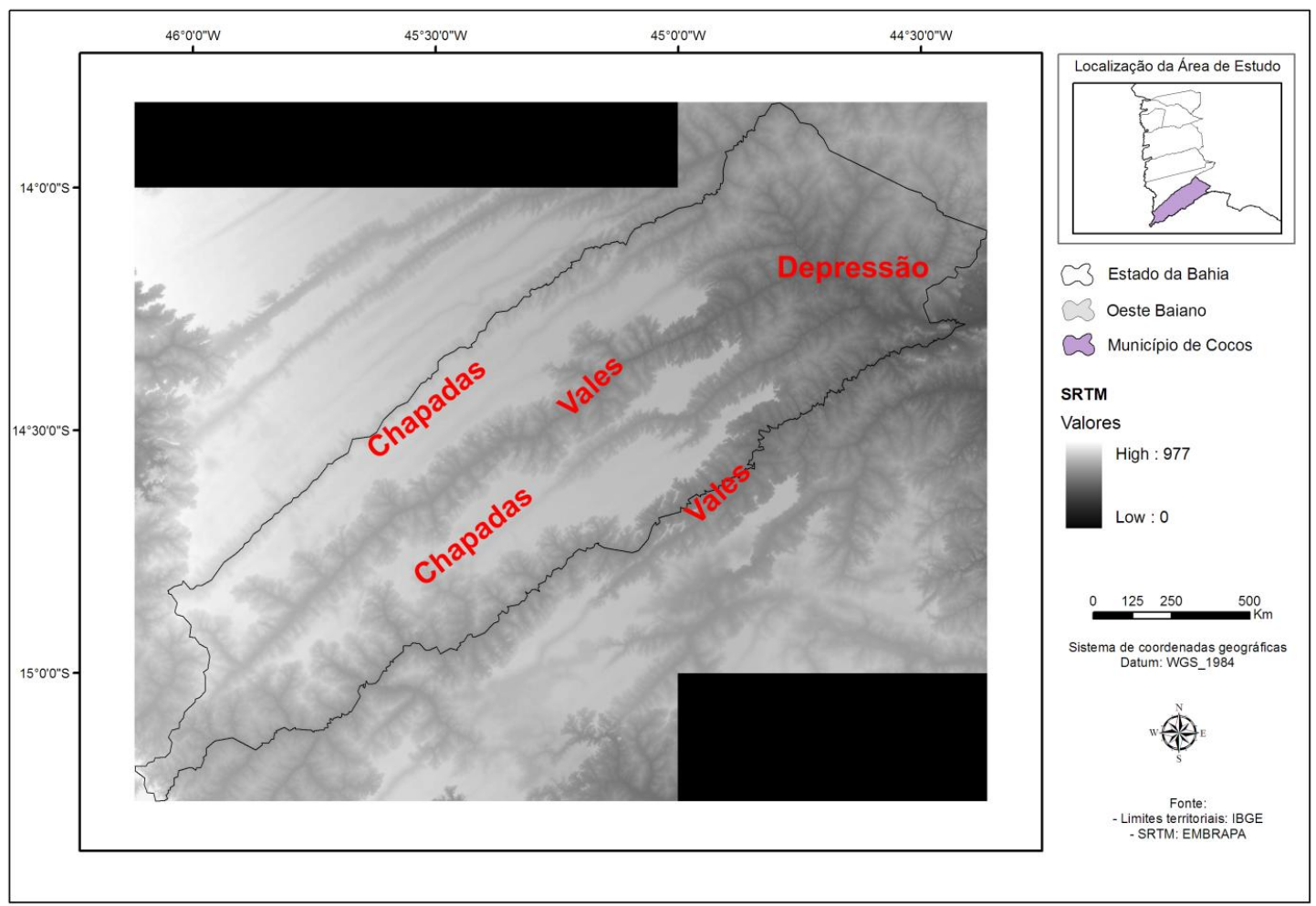

Figura 4 - Imagem do Modelo Digital de Terreno do município de Cocos com o posicionamento das unidades geomorfológicas: Chapadas, Vales e Depressão. 


\section{Mapa de Uso da Terra- 2004}

Em 2004 as áreas de vegetação (943.945,34 hectares - 93,617\%) mantiveram a tendência de perda, com a diminuição da vegetação nativa preservada (937.247,74 hectares - 92,95\%) (Figura 5). No entanto, a vegetação alterada apresentou uma diminuição devido à apropriação agrícola das áreas de vegetação anteriormente alterada (6.697,60 hectares - 0,66\%).

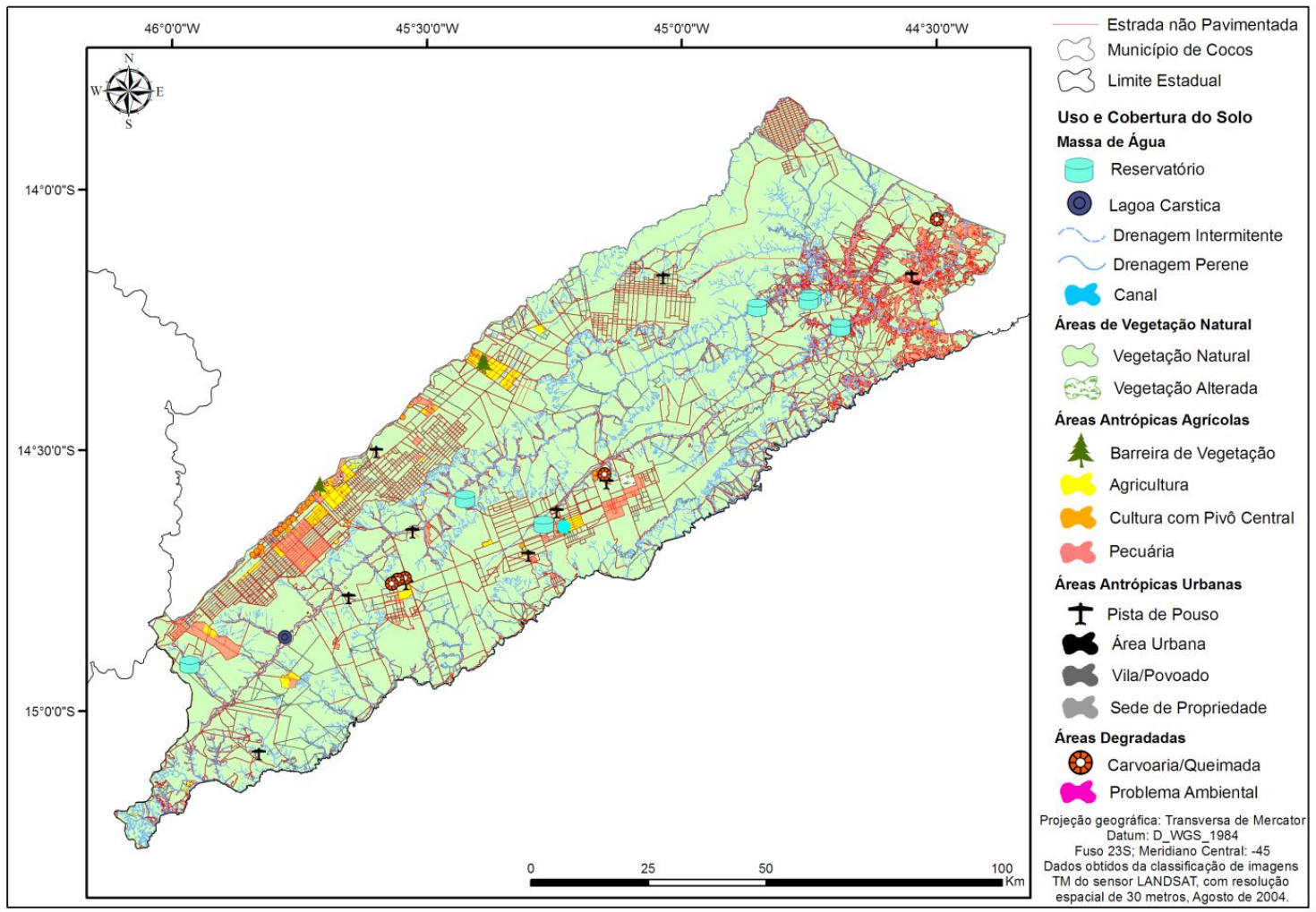

Figura 5 - Mapa de Uso e Cobertura do solo no município de Cocos, BA, em 2004.

As áreas antrópicas expandiram-se principalmente nas mesmas localidades descritas para o ano 2000: na porção sudeste próximo à sede municipal; e na porção oeste nas áreas de chapada. As áreas de agropecuária $(63.001,73$ hectares - 6,25\%) apresentaram significativo crescimento. A agricultura (14.321,78 hectares - 1,42\%) apresentou um expressivo crescimento (maior que 100\%), espacialmente correlacionada com a instalação da infraestrutura de estradas nas regiões de Chapada e o crescimento urbano. 
A irrigação por pivô central apresentou um tênue crescimento $(2.248,05$ hectares - 0,23\%), com 23 áreas cultivadas nas margens do Rio Formoso e do Riacho do Meio. A pecuária (46.431,09 hectares - 0,222\%) apresentou elevado aumento (maior que 100\%).

As áreas antrópicas urbanas $(240,26$ hectares - 0,024\%) descrevem pouco crescimento: das áreas urbanas (169,75 hectares - 0,017\%); e das vilas e povoados (70,51 hectares - 0,007\%).

As áreas degradadas mantiveram o crescimento, especialmente em áreas de fragilidade ambiental como nascentes e cursos de água intermitentes, somando 77,67 hectares $(0,008 \%)$. As áreas de corpos d'água mostraram-se inalteradas com relação a 2000.

\section{Mapa de Uso da Terra- 2008}

Em 2008 as tendências de evolução da paisagem foram em sua maioria mantidas (Figura 6). Observa-se a diminuição da vegetação (937.246 hectares - 92,94\%) principalmente das áreas de vegetação nativa preservada (922.382 hectares - 91,47\%). As vegetações alteradas apresentaram nova etapa de crescimento (14.864 hectares - 1,47\%), superior ao dobro de 2004 estando relacionada ao avanço da fronteira agrícola.

Entre 2004 e 2008 observou-se um menor crescimento nas áreas antrópicas urbanas (257 hectares - 0,026\%), um crescimento intermediário das áreas agrícolas (69.551,94 hectares - 6,9\%) e um maior crescimento das áreas degradadas (234 hectares - 0,023\%). As áreas dos corpos d'água mostraramse inalteradas ( 1.135 hectares). 


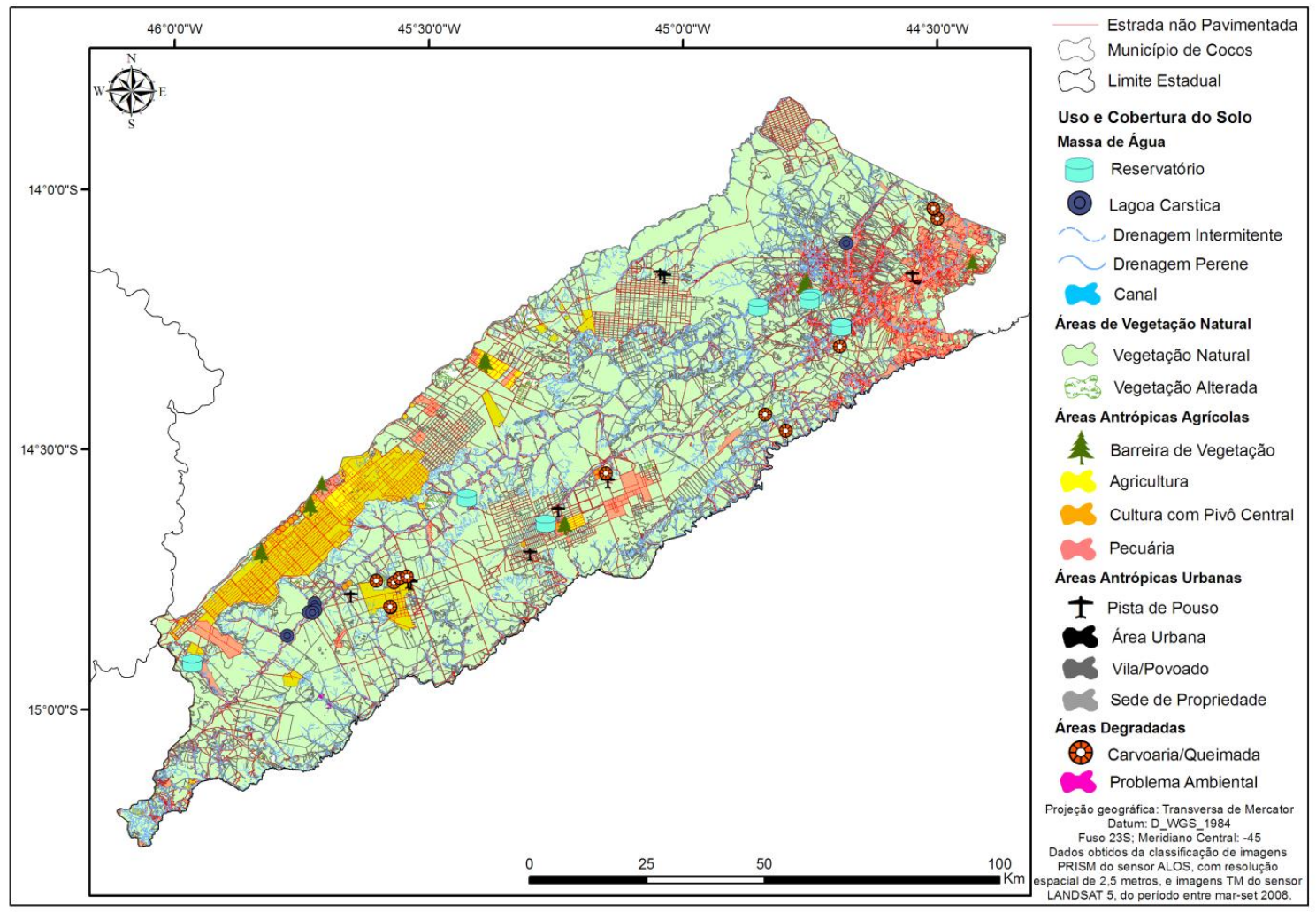

Figura 6 - Mapa de Uso e Cobertura do solo no município de Cocos, BA, em 2008.

\section{Sumário da evolução do uso e ocupação do solo 1996-2008}

A vegetação ao longo da série temporal demonstrou uma perda de 47.016 hectares. As áreas de vegetação alterada possuíram um comportamento variável relacionado com a dinâmica de abertura de fronteiras agrícolas e de efetivação da ocupação.

A agropecuária apresentou uma forte tendência de crescimento ao longo do tempo, sendo o principal vetor de alteração da paisagem natural, apresentando a seguinte evolução em porcentagem: 2,27\% (1996); 4,35\% (2000); 6,25\% (2004) e 6,9\% (2008).

As áreas de agricultura e pecuária apresentaram tendências temporais diferenciadas. As áreas de pecuária apresentaram uma evolução até $2004 \mathrm{e}$ sofreram uma acentuada queda em 2008 sendo: 1,82\% (1996); 3,56\% (2000); 
4,6\% (2004); e 2,4\% (2008). Esta acentuada redução relaciona-se com 0 crescimento das áreas de agricultura, sugerindo a conversão da pecuária em agricultura.

As áreas que mais evoluíram foram as de agricultura sendo: 0,44\% em 1996, 0,59\% em 2000, 1,42\% em 2004 e 4,27\% em 2008. As áreas de pivô central também apresentaram tendência de crescimento: 0,01\% em 1996; 0,2\% em 2000; 0,23\% em 2004; e 0,23\% em 2008.

As áreas antrópicas urbanas apresentaram tendência de crescimento sendo: $0,006 \%$ em 1996; 0,023\% em 2000, 0,024\% em 2004, e 0,026\% em 2008. As áreas urbanas ocupavam 0,001\% em 1996; 0,016\% em 2000; 0,017\% em 2004; e 0,019\% em 2008, enquanto as vilas e povoados ocupavam $0,005 \%$ em 1996; e 0,07\% em 2000, 2004 e 2008.

As áreas degradadas apresentaram crescimento, especialmente nos últimos anos da série temporal: 0,005\% em 1996; 0,007\% em 2000; 0,008\% em 2004; e 0,023\% em 2008. Houve crescimento das áreas de carvoarias e queimadas, que em 1996 e 2000 ocupavam 0,6 hectares; em 2004, 2,6 hectares; e em 20087 hectares. As áreas com erosões e áreas desmatadas ocupavam 0,005\% em 1996; 0,007\% em 2000; 0,0075\% em 2004; e 0,022\% em 2008.

\section{Análise da evolução temporal dos atributos de infraestrutura}

A instalação e o adensamento de estradas pavimentadas e de terra apresentaram uma alta correlação com a intensificação das atividades antrópicas. Dessa forma, as estradas sinalizam o processo de ocupação do território. As estradas são consideradas o principal vetor de ocupação agropecuária, fazendo a ligação entre as comunidades rurais, os centros de abastecimento e consumo, melhorando a qualidade de vida na região. $\mathrm{Na}$ área de estudo, as estradas apresentaram crescimento de sua extensão desde 1996 até 2008, com intensificação neste último ano da série temporal (Figura 7).

A abertura de estradas na paisagem essencialmente natural permitiu a instalação das primeiras atividades antrópicas, com a alteração da vegetação e 
desmatamentos. A instalação pontual de atividades antrópicas suscitou a abertura de novas estradas, de modo a interligar as ocupações humanas. 0 recorte da paisagem pelas estradas permitiu a instalação de manchas de atividades, especialmente agrícolas, garantindo o escoamento da produção e o abastecimento de insumos para a produção agropecuária.
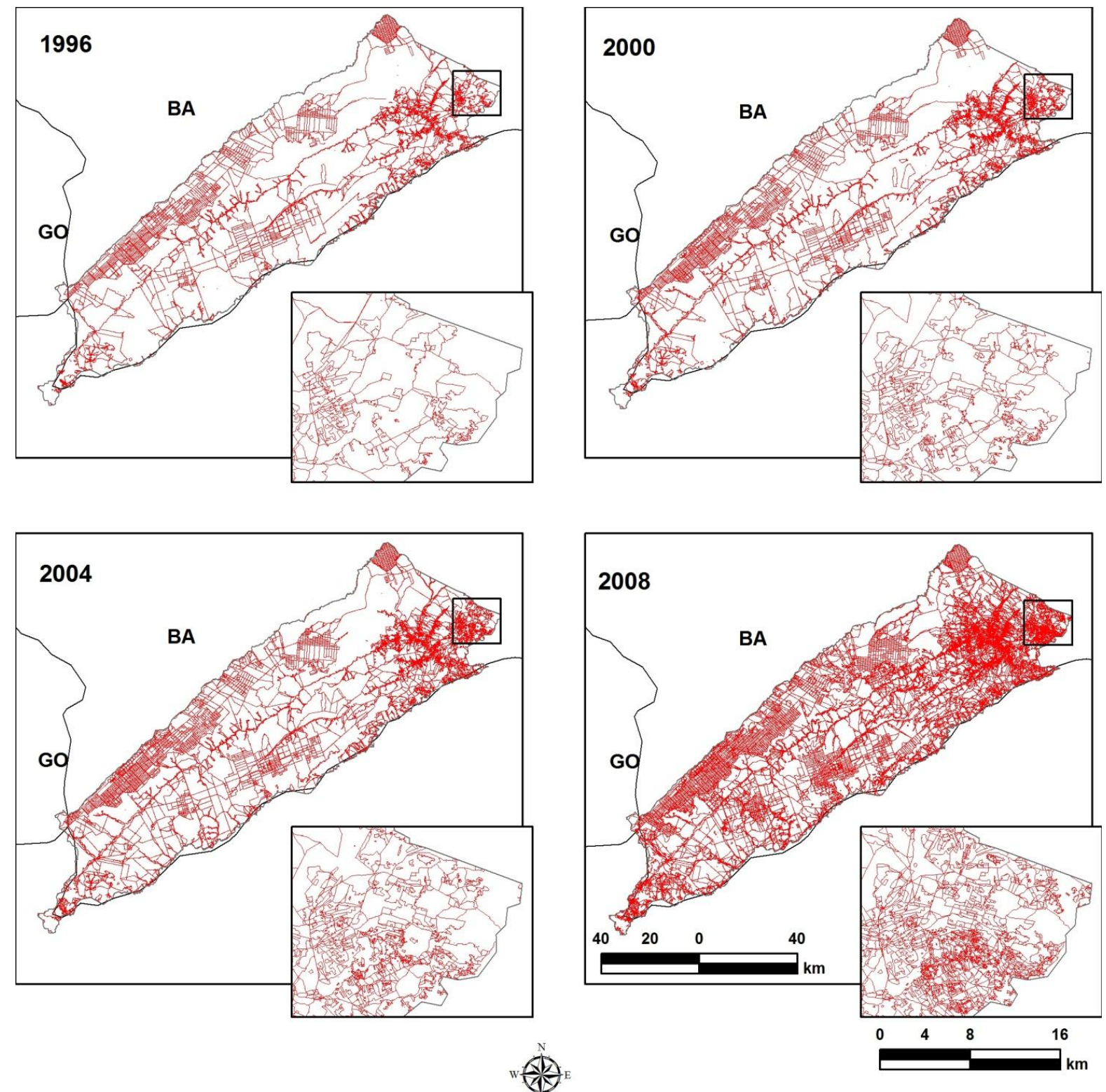

- Estrada não Pavimentada $\sim \mathcal{S}$ Limite Estadual $\sim \mathcal{B}$ Município de Cocos

Figura 7 - Adensamento das estradas pavimentadas e de terra no município de Cocos entre os anos de 1996 e 2008. 
Outros atributos de infraestrutura foram analisados complementarmente ao relativo às estradas: o número de propriedades rurais e o número de reservatórios. Estes indicadores, juntamente com a análise das estradas, permitiram detectar a instalação e fixação humana na região e, algumas vezes, antecipar o intuito de uso antes da instalação das atividades agropecuárias.

Os reservatórios relacionam-se ao adensamento das atividades agropecuárias, especialmente ao padrão produtivo com base na irrigação e com grandes áreas voltadas às culturas com pivô central. Este atributo apresenta crescimento no número de ocorrências na série temporal: com três ocorrências em 1996 e nove em 2008.

As sedes de propriedades apresentaram crescimento, relacionado ao crescimento das atividades antrópicas na região: em 1996 foram identificadas 306 sedes; em 2000, foram 427 sedes; em 2004, 544 sedes; e em 2008, 671 sedes de propriedades. Estas se apresentaram desigualmente distribuídas no território municipal, sendo numerosas nos Vales e em pequenos números nas Chapadas, representando enfoques produtivos diferenciados. As áreas de Chapada relacionaram-se à produção monocultora de café, algodão, soja e outros produtos voltados à exportação.

\section{Transformação dos ambientes naturais em antrópicos}

O presente estudo permite estabelecer uma trajetória consistente para 0 processo de desmatamento do Cerrado e da sua apropriação, principalmente, por empresários vinculados ao agronegócio e mercado exterior. As diferenças da paisagem tanto no fator topográfico como pedológico explicam a maior expansão das áreas agrícolas nas regiões de Chapada.

A dinâmica do uso e cobertura da terra no município de Cocos entre 1996 e 2008 demonstra que a primeira intervenção humana ocorreu na abertura do Cerrado nativo, normalmente a partir de queimadas $e$ desmatamentos, com a formação da vegetação alterada. Nesta etapa é comum a presença de carvoarias, que utilizam a vegetação como recurso econômico.

Nas regiões inicialmente alteradas observa-se o processo de instalação 
de estradas. $O$ adensamento das vias de acesso gera um parcelamento da paisagem e uma fragmentação do Cerrado. Neste cenário com estradas ortogonais, a ocupação espacial da agricultura ocorre inicialmente intercalada na paisagem, que progride para uma contínua mancha agrícola. A região noroeste da Chapada exemplifica este uso intensivo, onde inexistem em seu interior áreas preservadas.

$\mathrm{Na}$ medida em que a agricultura se expande aumentam o número das sedes de propriedades. As atividades antrópicas ficam cada vez mais especializadas, estruturando como parte da fronteira agropecuária do Oeste Baiano, que contrasta com a presença de grande remanescentes vegetais do Cerrado.

Somam-se às atividades agrícolas as concentrações urbanas em cidade e vilas/povoados e a instalação de canais e reservatórios, que dão suporte às atividades agrícolas e não-agrícolas.

\section{CONCLUSÕES}

O agronegócio é o setor da economia que mais tem contribuído para o desempenho favorável do comércio exterior brasileiro, com uma vasta gama de produtos. No entanto, torna-se fundamental que este desenvolvimento econômico esteja sobre uma premissa de planejamento ambiental.

$\mathrm{Na}$ área de estudo, a paisagem agrícola demonstra uma evolução similar aos municípios vizinhos que se caracterizam por extensas áreas contínuas de plantações. Esta configuração deve ser um alerta, de forma a não se estender para todo o município. A instalação de estradas aponta para a repetição dos padrões de paisagem agrícola nas circunvizinhas, demonstrando a replicação do processo de ocupação.

Portanto, os resultados gerados são úteis para os tomadores de decisão nas áreas do planejamento e desenvolvimento, tanto na esfera pública como privada. A conservação do Cerrado mostra-se dependente da relação das instituições governamentais e dos atores sociais. Assim torna-se fundamental a educação e conscientização dos agricultores em relação aos condicionantes 
legais de demarcações de reservas que realmente permita a sustentabilidade ambiental.

\section{REFERÊNCIAS BIBLIOGRÁFICAS}

ARAÚJO-FILHO, M. da C.; MENESES, P. R.; SANO, E. E. Sistemas de classificação de uso e cobertura da terra com base na análise de imagens de satélite. Revista Brasileira de Cartografia, n. 59/02, p. 171-179, 2009.

BAHIA, Superintendência de Estudos Econômicos e Sociais da Bahia (SEI). Banco de dados, mapas e cartogramas digitais. Salvador, BA: 2007. 20 Cartogramas. Escala: 1: 6500 000. Disponível em: <http://www.sei.ba.gov.br>. Acesso em 30 mar. 2009.

BATISTELLA, M.; ROBESON, S.; MORAN, E. F. Settlement design and landscape change in Amazônia: a multi-temporal evaluation using spatial metrics. Photogrammetric Engeneering and Remote Sensing, v. 69, n. 7, p. 805-812, 2003.

BENITE, E. V. A tecnologia espacial como ferramenta para o monitoramento ambiental: um caminho para 0 desenvolvimento sustentável. 2006. 152 f. Dissertação (Mestrado em Política e Gestão de Ciência e Tecnologia), Universidade de Brasília, UnB, Centro de Desenvolvimento Sustentável, CDS. Brasília, DF, 2006.

BERTRAND, G. Paysage et Geographie Physique Globale Esquisse méthodologique. Révue Geographique des pyrinées et Du Sud-Ouest. v. 39 n. 3, p. 249-272, 1968.

BRASIL, Ministério do Meio Ambiente, Secretaria de Biodiversidade e Florestas (MMA/SBF). Avaliação e identificação de áreas prioritárias para a conservação, utilização sustentável e repartição dos benefícios da biodiversidade nos biomas brasileiros. Brasília, DF, 2002, 404 p.

BRASIL. Ministério do Meio Ambiente, Secretaria de Biodiversidade e Florestas (MMA/SBF). Fragmentação de Ecossistemas: Causas e Efeitos sobre a Biodiversidade e Recomendações de Políticas Públicas. Brasília: MMA/SBF, 2003, 510 p.

BYRNE, G. F.; CRAPPER, P. F.; MAYO, K. K. Monitoring land cover change by principal component analysis of multitemporal Landsat data. Remote Sensing of Environment, v. 10, p. 175-184, 1980.

CAKIR, H. I.; KHORRAM, S.; NELSON, S. A. C. Correspondence analysis for detecting land cover change. Remote Sensing of Environment, v. 102, n. 3-4, p. 306-317, 2006.

CARVALHO JÚNIOR, O. A.; SAMPAIO, C. S.; SILVA, N.C. da; COUTO JUNIOR, A. F.; GOMES, R. A. T.; CARVALHO, A. P. F.; SHIMABUKURO, Y. E. 
Classificação de padrões de savana usando assinaturas temporais NDVI do sensor MODIS no Parque Nacional Chapada dos Veadeiros. Revista Brasileira de Geofísica, v. 26, n. 4, p. 505-517, 2008.

CARVALHO JÚNIOR, O. A.; HERMUCHE, P. M. \& GUIMARÃES R. F. Identificação regional da floresta estacional decidual na bacia do rio Paranã a partir da análise multitemporal de imagens MODIS. Revista Brasileira de Geofísica, v. 24, n. 3, p. 319-332, 2006.

CARVALHO JÚNIOR; O. A.; GUIMARÃES, R. F.; GILLESPIE, A. R.; SILVA, N. C.; GOMES, R. A. T. A New Approach to Change Vector Analysis Using Distance and Similarity Measures. Remote Sensing, v. 3, p. 2473-2493, 2011.

COHEN, W. B.; FIORELLA, M.; GRAY, J.; HELMER, E.; ANDERSON, K. An efficient and accurate method for mapping forest clearcuts in the Pacific Northwest using Landsat imagery. Photogrammetric Engineering and Remote Sensing, v. 64, n.4, p. 293-300, 1998.

COPPIN, P.; JONCKHEERE, I.; NACKAERTS, K.; MUYS, B.; LAMBIN, E. Review article digital change detection methods in ecosystem monitoring: a review. International Journal of Remote Sensing, v. 25, n. 9, p. 1565-1596, 2004.

COPPIN, P.; NACKAERTS, K.; QUEEN, L.; BREWER, K. Operational monitoring of green biomass change for forest management. Photogrammetric Engineering and Remote Sensing, v. 67, p. 603-611, 2001.

CREPANI, E.; MEDEIROS, J.S.; HERNANDEZ FILHO, P.; FLORENZANO, T.G.; DUARTE, V.; BARBOSA, C.C.F. Sensoriamento Remoto e Geoprocessamento Aplicados ao Zoneamento Ecológico-Econômico e ao Ordenamento Territorial. INPE-8454-RPQ-722, 2001, São José dos Campos: INPE, 2001, 124p.

DE BRUIN, S. Querying probabilistic land cover data using fuzzy set theory. International Journal of Geographical Information Sciences, v. 14, p. 359372, 2000.

FELFILI, J.M.; SILVA JÚNIOR, M.C. Biogeografia do bioma cerrado: estudo fitofisionômico da Chapada do Espigão Mestre do São Francisco. Brasília: Universidade de Brasília, 2001. 152p.

FERREIRA, L.V.; VENTICINQUE, E.; ALMEIDA, S.S. O desmatamento da Amazônia e a importância das áreas protegidas. Estudos Avançados. v. 19, n. 53. p. 157-166, 2005.

FORMAN, R. T. T. Land Mosaics: The Ecology of Landscapes and Regions. Cambridge, UK: Cambridge Univ. Press, 1995, 656p.

FUNG T \& LEDREW E. The application of principal components analysis to change detection using various accuracy indices. Photogrammetric Engineering and Remote Sensing. v. 53, p. 1649-1658, 1987.

FUNG, T.; LEDREW, E. The determination of optimal threshold levels for 
change detection using various accuracy indices. Photogrammetric Engineering and Remote Sensing, v. 54, n. 10, p. 1449-1454, 1988.

GONG, P.; LEDREW, E. F.; MILLER, J. R. Registration-noise reduction difference images for change detection. International Journal of Remote Sensing, v. 13, p. 773-779, 1992.

GORDON, S. Utilizing Landsat imagery to monitor land use change. Remote Sensing of Environment, v. 9, p. 189-196, 1980.

HOWARTH, P.J. \& MICKWARE, G.M. Procedures for change detection using Landsat digital data. International of Remote Sensing, v. 2, p. 277-279, 1981.

IGARASHI, T. ALOS mission requirement and sensor specifications. Advances in Space Research, v. 28, n. 1, p. 127-131, 2001.

JAXA. ALOS Product Format Description. 2006. Acessado em 7 Junho 2009. Disponível em: <http://stage.tksc.jaxa.jp/eorcalos/PRISM L1 J ENa.zip >.

JENSEN, J. R.; COWEN, D. J.; NARUMALANI, S.; ALTHAUSEN, J. D.; WEATHERBEE, O. An evaluation of Coastwatch change detection protocol in South Carolina. Photogrammetric Engineering and Remote Sensing, v. 59, p. 4, p. 519-525, 1993.

KLINK, C. A.; MACHADO, R. B. A conservação do Cerrado brasileiro. Megadiversidade, v. 1, n. 1, p. 147-155, 2005.

KOCAMAN, S.; GRUEN, A. Orientation and Self-calibration of ALOS PRISM Imagery. The Photogrammetric Record, v.23, n.123, p. 323-340, 2008.

LATORRE, M. L.; CARVALHO JUNIOR, O.A.; SANTOS, J. R.; SHIMABUKURO Y. E. Integração de dados de sensoriamento remoto multi resoluções para a representação da cobertura da terra utilizando campos contínuos de vegetação e classificação por árvores de decisão. Revista Brasileira de Geofísica, v. 25, n. 1, p. 63-74, 2007.

LAURENCE, W. F.; ALBERNAZ, A. L. K. M.; SCHROTH, G.; FEARNSIDE, P. M.; BERGEN, S.; VENTICINQUE, E. M.; COSTA, C. Predictors of deforestation in the Brazilian Amazon. Journal of Biogeography, v. 29, p. 1-12, 2002.

MACLEOD, R. D.; CONGALTON, R. G. A Quantitative Comparison of ChangeDetection Algorithms for Monitoring Eelgrass from Remotely Sensed Data. Photogrammetric Engineering \& Remote Sensing, v. 64, n. 3, p. 207-216, 1998.

MARTINELLI, M. Curso de Cartografia Temática. São Paulo: Contexto, 1991, $112 \mathrm{p}$.

MAS, J. F. Monitoring land-cover changes: a comparison of change detection techniques. International Journal of Remote Sensing, n. 18, p. 711-725, 1999.

MATTOS, J. C. F.; CARVALHO JUNIOR, O. A.; GUIMARÃES, R. F. Ecologia da paisagem voltada para o manejo de avifauna. Espaço e Geografia (UnB), 
Brasília, v. 2, p. 89-114, 2003.

MDA FEDERAL, Landsat GeoCover ETM+ 2000 Edition Mosaics Tile N-03-05. ETM-EarthSat-MrSID, 1.0, USGS, Sioux Falls, South Dakota, 2004.

MENKE, A. B.; CARVALHO JUNIOR, O. A.; GOMES, R.A.T.; MARTINS, E. S.; OLIVEIRA, S. N. Análise das mudanças do uso agrícola da terra a partir de dados de sensoriamento remoto multitemporal no município de Luis Eduardo Magalhães (Bahia - Brasil). Sociedade \& Natureza, v. 21, n. 3, p. 315-326, 2009.

MORA, F.; IVERSON, L. R. Dynamic stratification of the landscape of Mexico: analysis of vegetation patterns observed with multitemporal remotely sensed images. Geocarto International, v. 12, n. 73- 87, 1997.

MUNYATI, C. Wetland change detection on the Kafue Flats, Zambia, by classification of a multitemporal remote sensing image dataset. International Journal of Remote Sensing, v.21, n.9, p. 1787-1806, 2000.

NARUMALANI, S.; MISHRA, D. R.; ROTHWELL, R. G. Change detection and landscape metrics for inferring anthropogenic processes in the greater EFMO area. Remote Sensing of Environment, v.91, p.478-489, 2004.

PERZ, S. G.; SOUZA, J. R. C.; ARIMA, E.; CALDAS, M.; BRANDÃO, A.; SOUZA, K.; WALKER, R. O dilemas das estradas não oficiais na Amazônia. Ciência Hoje. v. 37, n. 222, p. 56-58, 2005.

REED, B. C.; BROWN, J. F.; VANDERZEE, D.; LOVELAND, T. R.; MERCHANT, J. W.; OHLEN, D. O. Measuring phenological variability from satellite imagery. Journal of Vegetation Science, v. 5, p. 703-714, 1994.

RIBEIRO, J. F.; WALTER, B. M. T. Fitofisionomias do Bioma Cerrado. In: SANO, S.M.; ALMEIDA, S. P. Cerrado: ambiente e flora. Planaltina, DF: EMBRAPA-CPAC, 1998, Capítulo 3, p. 89-166.

RIDD, M.K.; LIU, J. A comparison of four algorithms for change detection in an urban environment. Remote Sensing of Environment, v. 63, p. 95-100, 1998.

ROSA, R. Introdução ao sensoriamento remoto. 2. ed. Uberlândia, MG: EdUFU, 1992, 110 p.

SACHS, I. Desenvolvimento: includente, sustentável, sustentado. Rio de Janeiro: Garamond, 2004. 152p.

SADER, S. A.; BERTRAND, M.; WILSON, E. H. Satellite change detection of forest harvest patterns on an industrial forest landscape. Forest Science, v. 49, n. 3, p. 341-353, 2003.

SALES, V. de C. Geografia, sistemas e análise ambiental: abordagem crítica. Geousp - Espaço e Tempo, n. 16, p. 125-141, 2004.

SAMPAIO, C. S. Abordagem metodológica baseada nos dados multitemporais MODIS/EVI/NDVI para classificação da cobertura vegetal na região do Parque Nacional da Chapada dos Veadeiros/GO. 2007. 73 f. 
Dissertação (Mestrado em Geografia), Universidade de Brasília, UnB, Departamento de Geografia, GEA, Brasília, DF. 2007.

SANTANA, O.A.; CARVALHO JUNIOR, O.A.; GOMES, R.A.T.; CARDOSO, W.S.; MARTINS, E.S.; PASSO, D.P.; GUIMARÃES, R.F. Distribuição de espécies vegetais nativas em distintos macroambientes na região do Oeste da Bahia. Espaço e Geografia, v. 13, n. 2, p. 181-223, 2010.

SANTOS, F. J. dos. Gestão agroecológica de Microbacias, Através de Técnicas de Geoprocessamento e Sensoriamento Remoto - Caso Pantanoso. 1999. 84 f. Dissertação (Mestrado em Sensoriamento Remoto), Universidade Federal do Rio Grande do Sul, UFRGS, Centro Estadual de Pesquisas em Sensoriamento Remoto e Meteorologia, CEPSRM, Porto Alegre, RS. 1999.

SAUNDERS, S. C.; MISLIVETS, M. R.; CHEN, J.; CLELAND, D. T. Effects of roads on landscape structure within nested ecological units of the Northern Great Lakes Region, USA. Biological Conservation. v.103, p. 209-225, 2002.

SINGH, A. Digital change detection techniques using remotely-sensed data. International Journal of Remote Sensing, v. 10, p.989-100, 1989.

SKAKUN, R. S.; WULDER, M. A.; FRANKLIN, S. E. Sensitivity of the thematic mapper enhanced wetness difference index to detect mountain pine beetle redattack damage. Remote Sensing of Environment, v. 86, p. 433-443, 2003.

SOTCHAVA, V. B. O estudo de geossistemas. Métodos em Questão, Instituto de Geografia USP. São Paulo, v. 16, p. 1-52, 1977.

SOUZA JR, C.; BRANDÃO, A.; ANDERSON, A.; VERÍSSIMO, A. Avanço das estradas endógenas na Amazônia. Amazônia em Foco. Manaus: Imazon, n. 1, p.1-2, 2004.

WEISMILLER, R. A.; KRISTOF, S. J.; SCHOLZ, P. E.; ANUTA, P. E.; MOMIN, S. A. Change detection in coastal zone environments. Photogrammetric Engineering and Remote Sensing, v. 43, p. 1533-1539, 1977.

XAVIER-DA-SILVA, J. Geoprocessamento para análise ambiental. Rio de Janeiro: Edição do autor, 2001, 228p.

YUAN F, SAWAYA KE, LOEFFELHOLZ, B \& BAUER ME. Land cover classification and change analysis of the Twin Cities (Minnesota) metropolitan area by multitemporal Landsat remote sensing. Remote Sensing of Environment, v. 98, n. 2, p.317-328, 2005. 